\title{
Reduction of baseline body mass index under gonadotropin-suppressive therapy in girls with idiopathic precocious puberty
}

Teresa Arrigo, Filippo De Luca, Franco Antoniazzi ${ }^{1}$, Fiorella Galluzzi ${ }^{2}$, Maria Segni ${ }^{3}$, Maria Rosano, Maria Francesca Messina and Fortunato Lombardo

Departments of Pediatrics, Universities of Messina, ${ }^{1}$ Verona, ${ }^{2}$ Florence and ${ }^{3}$ Rome, Italy

(Correspondence should be addressed to F De Luca, Dipartimento di Scienze Pediatriche Mediche e Chirurgiche, Policlinico Universitario, 98123 Messina, Italy; Email: filippo.deluca@unime.it)

\begin{abstract}
Objective: To investigate longitudinally body mass index (BMI) evolution and obesity prevalence in a large and very homogeneous study population consisting only of girls with non-organic central precocious puberty (CPP) who were treated with gonadotropin-releasing hormone agonists (GnRHa) for at least two years.

Patients and design: The 101 girls with idiopathic CPP who were selected for this study fulfilled the following inclusion criteria: (a) suppression of gonadotropin and gonadal sex steroid secretion during the overall GnRHa treatment period; (b) adequate compliance with the therapy regimen. All the girls were treated for $44 \pm 14$ months and were followed-up for $15.7 \pm 7.8$ months after therapy withdrawal.

Results: At the start of therapy, $23.8 \%$ of the girls had a BMI exceeding 2 standard deviation scores (SDS) and were therefore classified as obese; both average BMI-SDS and obesity prevalence significantly decreased during the treatment period $\left(\chi^{2}=16.6, P<0.0005\right)$ and only $4 \%$ of the patients, all with pre-existing obesity, were still obese at the end of therapy; during the therapy period, BMI-SDS increased in none of the patients. Both average BMI-SDS and obesity prevalence (from 4 to $0 \%$; $\left.\chi^{2}=4.0, P<0.05\right)$ further decreased during the period that followed therapy withdrawal.

Conclusions: (a) girls with idiopathic CPP are frequently obese at the onset of GnRHa therapy (23.8\%), probably due to the hormonal changes which accompany the start of puberty; (b) their obesity is neither long-lasting nor related to GnRHa administration; (c) on the contrary, GnRHa therapy may have a favourable effect on BMI decrease, provided that treatment is performed for at least two years and is accompanied by a complete suppression of gonadotropin secretion; (d) this unexpected effect, which has never been reported hitherto, might represent a further indication for GnRHa administration in idiopathic CPP.
\end{abstract}

European Journal of Endocrinology 150 533-537

\section{Introduction}

Rapidly progressive forms of idiopathic central precocious puberty (CPP) need to be treated because of the psychosocial problems in the family and the affected children (1) and because of the development of short stature and associated body disproportion due to premature epiphyseal fusion (2).

Depot preparations of gonadotropin-releasing hormone (GnRH) agonists (GnRHa) have become the treatment of choice for CPP since the mid-1980s, although follow-up investigations have shown different results with regard to the effects and benefits of this therapy.

Much of the past research concerning the auxological effects of treatment with GnRHa in CPP has focused on the assessment of final height (3-8). Much less attention has been paid to the changes in weight and body composition. However, concerns have been expressed that CPP may be associated with increased body mass index (BMI) both at initial presentation and during GnRHa treatment (9) and that this condition may persist after therapy withdrawal, progressing to frank obesity (10). The results of other studies have confirmed that children with CPP are prone to the development of obesity $(7,11)$, but this predilection has not been demonstrated to be related to GnRHa administration (12).

The aim of this prospective and multicentric study was to investigate longitudinally BMI evolution and obesity prevalence in a large cohort of girls with 
idiopathic CPP who were treated with GnRHa for at least two years.

\section{Patients and methods}

\section{Patients}

This prospective study covers 101 girls with idiopathic CPP whose auxological and hormonal data at the start of treatment and during follow-up are summarized in Table 1. At treatment onset all patients had a history of increased growth velocity (GV) and a breast development of Tanner stage 2 or more $(2.8 \pm 0.4)$. In all cases, bone age (BA) was advanced more than one year beyond chronological age (CA) and the average $\mathrm{BA}: \mathrm{CA}$ ratio was more than 1 (Table 1 ).

The main criteria for diagnosis of idiopathic CPP have been: (a) onset of breast development and/or menses before 8 years of age (mean $6.8 \pm-0.8$, range 3.1-7.8); (b) pubertal luteinizing hormone (LH) response to exogenous $\mathrm{GnRH}$ (LH peak $>10$ IU/l) (13); (c) a ratio of stimulated LH:stimulated follicle-stimulating hormone (FSH) of more than 1.0 $(14,15)$; (d) no clinical signs and/or history of organic CPP; (e) no evidence of hypothalamo-pituitary lesions at magnetic resonance imaging (MRI); (f) no additional conditions that might affect puberty onset and/or BMI (e.g. primary hypothyroidism, congenital adrenal hyperplasia or growth hormone deficiency).

The hormonal criteria for the assessment of pubertal status have been established on the basis of international reports $(13-15)$ and have been validated in our department laboratories.

All the girls with idiopathic CPP who were selected for the present study fulfilled the following inclusion criteria: (a) suppression of gonadotropin and gonadal sex steroid secretion throughout the overall period of GnRHa treatment; (b) adequate compliance with the GnRHa regimen, as judged by GV decrease, parental report and record of medication administration.

\section{Study design}

After the initial evaluation, the patients received the same therapy (decapeptyl depot, D-Trp6-GnRH, IPSEN-Biotech, Milan, Italy) at a dose of $60 \mu \mathrm{g} / \mathrm{kg}$ i.m. every 28 days. Average CA at the start of treatment was 7.5 \pm 0.9 years (range 3.3-8.9). The average time interval between the first symptoms of early puberty and the start of treatment was 8.5 0.2 months (range 3-26 months). All the girls were treated for at

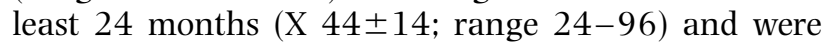
followed for $15.7 \pm 7.8$ months (range 6-42) after therapy withdrawal. Before treatment initiation, the patients underwent clinical, auxological (height, weight, BMI, BA), hormonal and neuroradiological evaluations. The hormonal examination at entry included basal and GnRH-stimulated levels of gonadotropins and basal levels of 17- $\beta$ estradiol (E2). Neuroradiological examination was based on MRI of the hypothalamo-pituitary region. Auxological measurements were again performed every 6-12 months throughout the treatment period and during the period which followed therapy withdrawal. Hormonal suppression under GnRHa therapy was validated by repeating the GnRH stimulation test three months after the start of treatment and by measuring only baseline gonadotropin and E2 concentrations every 6 months during treatment.

This study design was approved by our hospitals' ethical committees and written consent was obtained from the parents of patients.

\section{Methods}

Heights were measured with Harpenden stadiometers (Holtain Ltd, Crymmith, UK) and compared with agematched reference values for girls (16). The same Tanner's reference values were used for the assessment of weight, GV and pubertal stages (16). Bone age of all the girls was assessed by the same investigator using

Table 1 Chronological age (CA), bone age (BA), BA:CA ratio, height $(\mathrm{H})$, growth velocity (GV), weight (W), luteinizing hormone (LH) and estradiol (E2) serum levels at the 1st examination (before therapy onset), at the 2nd examination (at the end of therapy period) and at the 3rd examination (at the end of the entire follow-up period) in 101 girls with idiopathic CPP. $n=$ the number of cases at each examination. Results are means \pm S.D.

\begin{tabular}{|c|c|c|c|c|c|}
\hline & 1st examination $(n=101)$ & 2nd examination $(n=101)$ & $\boldsymbol{P}$ & 3rd examination $(n=101)$ & $\boldsymbol{P}$ \\
\hline CA (years) & $75 \pm 0.9$ & $11.2 \pm 0.9$ & & $12.4 \pm 0.7$ & \\
\hline BA (years) & $9.8 \pm 1.2$ & $12.4 \pm 0.5$ & & $13.6 \pm 0.6$ & \\
\hline $\mathrm{BA}: \mathrm{CA}$ ratio & $1.25 \pm 0.15$ & $1.06 \pm 0.08$ & $<0.0005$ & $1.02 \pm 0.06$ & $<0.0005$ \\
\hline H-SDS & $2.1 \pm 1.1$ & $1.1 \pm 1.0$ & $<0.0005$ & $-0.7 \pm 0.8$ & $<0.0005$ \\
\hline GV-SDS & $1.6 \pm 1.0$ & $-1.3 \pm 2.0$ & $<0.0005$ & $-1.8 \pm 0.9$ & $<0.01$ \\
\hline W-SDS & $1.5 \pm 1.1$ & $1.0 \pm 1.1$ & n.s. & $-0.6 \pm 0.8$ & $<0.005$ \\
\hline $\mathrm{LH}(\mathrm{IU} / \mathrm{I})$ & $2.9 \pm 1.3$ & $0.3 \pm 0.1$ & $<0.0005$ & $2.3 \pm 1.5$ & $<0.0005$ \\
\hline E2 (pmol/l) & $78.3 \pm 41.2$ & $24.2 \pm 6.1$ & $<0.0005$ & $52.4 \pm 56.5$ & $<0.0005$ \\
\hline
\end{tabular}

Significance levels were calculated respectively between the 1 st and the 2nd examination and between the 2nd and the 3 rd examination. n.s., not significant. 
an X-ray of the left hand, according to the method of Greulich and Pyle (17).

The nutritional status of the patients during the overall study period was assessed by means of BMI, which was calculated as weight $(\mathrm{kg}) /$ height $\left(\mathrm{m}^{2}\right)$ and was expressed in standard deviation scores (SDS), according to the standards assessed by Rolland-Cachera et al. (18). Serum LH, FSH and E2 were measured by the same enzyme immunoassays (LH and FSH, Bioserv Diagnostics, Rostock, Germany; E2, Research Diagnostics Inc., Flanders, USA) in the four different local endocrine laboratories of our hospitals. The sensitivities of the enzyme immunoassays were $0.3 \mathrm{IU} / \mathrm{l}$ for $\mathrm{LH}$ and FSH and $15 \mathrm{pmol} / \mathrm{l}$ for E2. Values of $0.2 \mathrm{IU} / \mathrm{l}$ (for LH and $\mathrm{FSH}$ ) and $14 \mathrm{pmol} / \mathrm{l}$ (for E2) were assigned to the sample below the detection limit. Pituitary-gonadal axis function under treatment was considered as adequately suppressed if LH and E2 values were maintained within the prepubertal normal ranges for our laboratories, i.e. if: a) stimulated LH serum levels were $<5 \mathrm{IU} / \mathrm{l}$; b) baseline LH levels were $<0.5 \mathrm{IU} / \mathrm{l}$; and c) E2 serum concentrations were $<50 \mathrm{pmol} / \mathrm{l}$.

\section{Statistical analyses}

For statistical purposes, Student's paired t-test, Wilcoxon test, and chi-square test were used when appropriate in order to estimate differences between groups. Correlations on individual values were made by Pearson's test. All values are given as means \pm S.D.

\section{Results}

\section{Auxological and hormonal data during follow-up}

The BA:CA ratio significantly and progressively decreased from the 1st to the 3rd examination, as did height and GV (Table 1).

During the same follow-up period, weight decrease from the 2 nd to the 3rd examination was highly significant, whereas its reduction from the 1 st to the 2 nd evaluation did not achieve statistical relevance (Table 1).

As far as hormonal status is concerned both baseline LH and E2 serum levels significantly decreased after the onset of therapy, whereas a relevant rebound was observed after GnRHa therapy withdrawal (Table 1).

\section{BMI and obesity prevalence during follow-up}

BMI and obesity prevalence data in the whole study population during the entire follow-up period are summarized in Table 2.

At the time of therapy initiation, the BMI-SDS was, on average, very high and $24 / 101$ patients $(23.8 \%)$ had a BMI exceeding 2 SDS and were therefore classified as obese.

BMI-SDS at the onset of therapy positively correlated with both height-SDS $(r=0.34, P<0.001)$ and BA at the same time-point $(r=0.31, P<0.01)$.

Both average BMI-SDS and obesity prevalence $\left(\chi^{2}=16.6, P<0.0005\right)$ significantly decreased from the 1 st to the 2 nd examination, i.e. at the end of the treatment period (Table 2). The four girls with persisting obesity were already obese at the onset of treatment. Moreover, BMI-SDS did not increase during the therapy period in any of the patients.

BMI-SDS at the end of treatment was positively associated with BMI-SDS at entry $(r=0.53$, $P<0.001)$ and negatively with treatment duration $(r=-0.41, P<0.001)$.

BMI-SDS and obesity prevalence $\left(\chi^{2}=4.0\right.$, $P<0.05)$ further decreased from the 2 nd to the 3 rd examination, i.e. at the end of the entire follow-up period (Table 2). During the overall study period (an average of $60.2 \pm 10.1$ months), the obesity prevalence decreased from 23.8 to $0 \%\left(\chi^{2}=27.2, P<0.0005\right)$ and no girl at the end of the follow-up period was still obese.

Finally, BMI-SDS at the end of the follow-up period was positively related to both the initial BMI-SDS ( $r=0.31, P<0.01)$ and the value recorded at the end of treatment $(r=0.59, P<0.001)$.

\section{Discussion}

The aims of the present study were to prospectively evaluate whether obesity occurs at a high rate among children with CPP, as reported in recent papers (12, 19 ), and whether a constantly and fully suppressed hypothalamo-pituitary-gonadal axis in CPP may have negative repercussions on the evolution af obesity, as observed by other authors, especially in patients with hypothalamic hamartoma (10).

In order to elucidate these two points, we have put together a large and very homogeneous study

Table 2 Body mass index (BMI) and obesity prevalence at the 1st examination (before therapy onset), at the 2nd examination (at the end of therapy period) and at the 3rd examination (at the end of the entire follow-up period) in 101 girls with idiopathic CPP. $n=$ the number of cases at each examination.

\begin{tabular}{|c|c|c|c|c|c|}
\hline & 1st examination $(n=101)$ & 2nd examination $(n=101)$ & $\boldsymbol{P}$ & 3rd examination $(n=101)$ & $\boldsymbol{P}$ \\
\hline $\begin{array}{l}\text { BMI-SDS (mean } \pm \text { S.D.) } \\
\text { BMI (range) }\end{array}$ & $\begin{array}{c}1.39 \pm 1.07 \\
\text { from }-1.02 \text { to } 5.03\end{array}$ & $\begin{array}{c}0.61 \pm 0.79 \\
\text { from }-1.20 \text { to } 2.81\end{array}$ & $<0.0005$ & $\begin{array}{c}0.11 \pm 0.52 \\
\text { from }-1.05 \text { to } 2.39\end{array}$ & $<0.0005$ \\
\hline Obesity prevalence (\%) & 23.8 & 4.0 & $<0.0005$ & 0 & $<0.05$ \\
\hline
\end{tabular}

Significance levels were calculated respectively between the 1 st and the 2 nd examination and between the 2nd and the 3rd examination. 
population consisting of only female subjects with idiopathic CPP, and have turned our specific attention to the changes in weight and BMI that accompany a prolonged GnRHa administration (at least two years).

Only the girls who had exhibited a full and constant pituitary-gonadal suppression under this treatment were included in our study population.

Our results as a whole have confirmed that obesity is a common problem in children with CPP (11, 20). Indeed, in the present study a quarter of our patients were found to be frankly obese before the institution of therapy and only a few girls in the entire study population had pre-treatment BMI-SDS lower than the average values for $\mathrm{CA}$.

The reasons why so many girls with CPP have an increased BMI at the start of therapy are not quite clear. Unfortunately, we have insufficient data regarding the subjects' BMI before their exposure to a pubertal sex steroid milieu. Nevertheless, it might be hypothesized that BMI was already elevated at the time of puberty onset in a fair proportion of our patients and this may possibly have played a favourable role in CPP development. According to Frisch's 'critical weight hypothesis', a certain percentage of body fat is needed for the onset of menarche, and obese girls have earlier menarche than thin girls $(21,22)$. Since BMI is a reliable index of body fatness (23), it is not surprising, therefore, that we and others (24) have found a significant association between overweight and CPP before therapy onset. This view is substantiated by the relevant relationships found in our patients between BMI and both height and BA at the 1st examination. These findings suggest that both stature and BA were more advanced at puberty onset in those girls with the highest BMI.

In the last years, however, the 'critical weight hypothesis' has been questioned and criticized (25, 26) and the current evidence linking fatness and pubertal events do not confirm the direction of causation that had been hypothesized by Frisch and Revelle (21). On the contrary, according to the most recent studies, it is the maturation timing that affects body composition $(27,28)$, probably through the hormonal changes associated with sexual maturation, which promote the development of adipose tissue (24).

Our present results concerning the effects of GnRHa treatment on the prevalence of obesity in girls with CPP add new insights into this issue and provide additional evidence for the influence of sexual maturation on fatness. The suppression of pituitary-gonadal axis function was accompanied in our series by a significant decrease in overweightness. This suggests that pre-treatment increase in BMI was due to the pubertal hormonal changes and secondary changes in body fat, rather than being a reason for CPP.

As it concerns the influences of GnRHa treatment on the evolution of baseline overweight, the available data in the literature are very controversial. According to
Heger et al. (19), obesity in CPP does not seem to be either caused or aggravated by this treatment. According to the conclusions of Palmert et al. (11), the available data indicate that BMI in a population of children with CPP does not change significantly during GnRHa administration, although some individuals may experience significant increases and decreases during the course of therapy. The results of another more recent study (12) demonstrate that, after an initial aggravation of adiposity which follows GnRHa therapy onset, no prolonged negative effects are detectable. Recently, Lazar et al. (29) have shown that GnRHa administration causes a significant weight gain, if compared with untreated patients. According to that report, however, the weight gain caused by this treatment is only temporary and should not be a reason for sparing therapy (29).

In the present study, GnRHa therapy did not have a negative impact on the evolution of baseline BMI in any of the patients. On the contrary, in our series this treatment was accompanied by a significant reduction of adiposity, and only few patients, all with a pre-existing obesity, were still noted to be obese at therapy withdrawal.

Ours is the first study that has been able to document a reductive effect of GnRHa treatment on the prevalence of baseline obesity. It is to be reiterated, however, that our investigation was based on a numerous and very homogeneous patient cohort that included only girls with non-organic CPP who were treated for at least two years, i.e. a sufficiently prolonged therapy duration. This last point is very important, in the light of the negative relationship found between BMI at treatment withdrawal and therapy duration. This correlation, in fact, suggests that a reduction of BMI under GnRHa treatment may be observed only in those cases who are treated for a long time.

Finally, our current data have demonstrated that BMI further decreased and normalized after treatment arrest and that none of the girls was still obese at the last evaluation. A significant decrease of BMI two years after cessation of treatment has also recently been reported by van der Sluis et al. (12), although in that report average BMI was still supranormal at the end of follow-up.

To summarize, on the basis of our results we can conclude that: (a) girls with idiopathic CPP may frequently be obese at puberty onset probably due to the hormonal changes which accompany the start of puberty; (b) their obesity is neither long-lasting nor related to GnRHa administration; (c) on the contrary, GnRHa therapy may have a favourable effect on BMI decrease, provided that treatment is performed for at least two years and is accompanied by a complete suppression of gonadotropin secretion; (d) this unexpected effect, which has never been reported hitherto, might represent a further indication for GnRHa administration in idiopathic CPP. 


\section{References}

1 Sonis WA, Comite F, Blue J, Pescovitz OH, Rahn CW, Hench KD et al. Behavior problem and social competence in girls with true precocious puberty. Journal of Pediatrics 1985106 156-160.

2 Sigurjonsdottir TJ \& Hayles AB. Precocious puberty. A report of 96 cases. American Journal of Disease in Childhood 1968115 309-321.

3 Antoniazzi F, Cisternino M, Nizzoli G, Bozzola M, Corrias A, De Luca $\mathrm{F}$ et al. Final height in girls with central precocious puberty: comparison of two different luteinizing hormone-releasing hormone agonist treatments. Acta Paediatrica $1994 \mathbf{8 3}$ $1052-1056$.

4 Arrigo T, Cisternino M, Galluzzi F, Bertelloni S, Pasquino AM, Antoniazzi F et al. Analysis of the factors affecting the auxological response to GnRH agonist treatment and final height outcome in girls with idiopathic central precocious puberty. European Journal of Endocrinology 1999141 140-144.

5 Bertelloni S, Baroncelli GI, Sorrentino MC, Perri G \& Saggese G. Effect of central precocious puberty and gonadotropin-releasing hormone analogue treatment on peak bone mass and final height in females. European Journal of Pediatrics $1998 \mathbf{1 5 7}$ 363-367.

6 Brauner R, Adan L, Malandry F \& Zantleifer D. Adult height in girls with idiopathic true precocious puberty. Journal of Clinical Endocrinology and Metabolism $1994 \mathbf{7 9} 415-420$.

7 Oostdijk W, Rikken B, Screuder S, Otten B, Odink R, Rouwè C et al. Final height in central precocious puberty after long term treatment with a slow release GnRH agonist. Archives of Disease in Childhood 199675 292-297.

8 Paul D, Conte FA, Grumbach MM \& Kaplan SL. Long term effect of gonadotropin-releasing hormone agonist therapy on final and near-final height in 26 children with true precocious puberty treated at a median age of less than 5 years. Journal of Clinical Endocrinology and Metabolism $199580546-551$.

9 Boot AM, de Muinck Keizer-Schrama S, Pols HA, Krenning EP \& Drop SL. Bone mineral density and body composition before and during treatment with gonadotropin-releasing hormone agonist in children with central precocious puberty and early puberty. Journal of Clinical Endocrinology and Metabolism $1998 \mathbf{8 3}$ $370-373$.

10 Feuillan PP, Jones JV, Barnes K, Oerter-Klein K \& Cutler GB. Reproductive axis after discontinuation of gonadotropin-releasing hormone analog treatment of girls with precocious puberty: long term follow-up comparing girls with hypothalamic hamartoma to those with idiopathic precocious puberty. Journal of Clinical Endocrinology and Metabolism $1999 \mathbf{8 4}$ 44-49.

11 Palmert MR, Mansfield MJ, Crowley WF, Crigler JF, Crawford JD \& Boepple PA. Is obesity an outcome of gonadotropin-releasing hormone agonist administration? Analysis of growth and body composition in 110 patients with central precocious puberty. Journal of Clinical Endocrinology and Metabolism $1999 \mathbf{8 4} 4480-4488$.

12 van der Sluis IM, Boot AM, Krenning EP, Drop SL \& Muinck Keizer-Schrama SMPF. Longitudinal follow-up of bone density and body composition in children with precocious or early puberty before, during and after cessation of GnRH agonist therapy. Journal of Clinical Endocrinology and Metabolism $2002 \mathbf{8 7}$ 506-512.

13 Partsch CJ, Hümmelink R \& Sippell WG. Reference ranges of lutropin and follitropin in the luliberin test in prepubertal and pubertal children using a monoclonal immunoradiometric assay. Journal of Clinical Chemistry and Clinical Biochemistry 199028 2849-2852.

14 Partsch CJ, Hümmelink R, Lorenzen F \& Sippell WG. Bedeutung und Carakteristika des LH-RH-Testes in der Diagnostik der vorzeitigen Pubertätsentwicklung bei Mädchen: Der stimulierte LH/FSH-Quotient differenziert zwischen Pubertas praecox und praematurer Thelarche. Monatsschrift Kinderheilkunde 1989137 $284-288$.

15 Pescovitz OH, Hench KD, Barnes KM, Loriaux DL \& Cutler GB. Premature menarche and central precocious puberty: the relationship between clinical presentation and the gonadotropin response to luteinizing-hormone releasing hormone. Journal of Clinical Endocrinology and Metabolism 1988 67 474-479.

16 Tanner JM \& Whitethouse RH. Clinical longitudinal standards for height, weight, height velocity, weight velocity, and stages of puberty. Archives of Diseases of Childhood $1976 \mathbf{5 1}$ 170-179.

17 Greulich WW \& Pyle SI. Radiographic Atlas of Skeletal Development of the Hand and Wrist, 2nd ed. Stanford, CA: Stanford University Press, 1959.

18 Rolland-Cachera MF, Cole TJ, Sempe M, Tichert J, Rossignol C \& Charraud A. Body mass index variations: centiles from birth to 87 years. European Journal of Clinical Nutrition 199145 13-21.

19 Heger S, Partsch CJ \& Sippel WG. Long-term outcome after depot gonadotropin-releasing hormone agonist treatment of central precocious puberty: final height, body proportions, body composition, bone mineral density, and reproductive function. Journal of Clinical Endocrinology and Metabolism 1999 84 4583-4590.

20 Chiumello G, Brambilla P, Guarneri MP, Russo G, Manzoni P \& Sgaramella P. Precocious puberty and body composition: effects of GnRH analog treatment. Journal of Pediatric Endocrinology and Metabolism 200013 (Suppl. 1) 791-794.

21 Frisch RE \& Revelle R. Height and weight at menarche and a hypothesis of critical body weights and adolescent events. Science 1970169 397-399.

22 Frisch RE. The right weight: body fat, menarche, and fertility. Nutrition $199612452-453$.

23 Rolland-Cachera MF. Body composition during adolescence: methods, limitations and determinants. Hormone Research 1993 39 25-40.

24 Wang Y. Is obesity associated with early sexual maturation? A comparison of the association in American boys versus girls. Pediatrics $2002110903-910$.

25 Bronson FH \& Manning JM. The energetic regulation of ovulation: a realistic role for body fat. Biology of Reproduction $1991 \mathbf{4 4}$ 945-950.

26 De Ridder CM, Thijssen JH, Bruning PF, Van den Brande JL, Zonderland ML \& Erich WB. Body fat mass, body fat distribution, and pubertal development: a longitudinal study of physical and hormonal sexual maturation of girls. Journal of Clinical Endocrinology and Metabolism 199275 442-446.

27 Kaplowitz PB, Slora EJ, Wasserman RC, Pedlow SE \& Herman-Giddens ME. Earlier onset of puberty in girls: relation to increased body mass index and race. Pediatrics $2001 \mathbf{1 0 8}$ 347-353.

28 Van Lenthe FJ, Kemper CG \& van Mechelen W. Rapid maturation in adolescence results in greater obesity in adulthood: the Amsterdam Growth and Health Study. American Journal of Clinical Nutrition $19966418-24$.

29 Lazar L, Kauli R, Pertzelan A \& Phillip M. Gonadotropin-suppressive therapy in girls with early and fast puberty affects the pace of puberty but not total pubertal growth or final height. Journal of Clinical Endocrinology and Metabolism 200287 2090-2094.

Received 26 August 2003

Accepted 30 December 2003 